\title{
Influence of Oscillating Packing Instrument on Microhardness of Bulk-Fill Composite: In Vitro Study
}

\author{
Emad Mohamed Bayoumi ${ }^{1 *}$, Mohamed Farid Riad ${ }^{2}$, Mohamed Mostafa Zayed $^{3}$, MostafaAbou Shelib $^{4}$, Ahmed Mohamed Bayoumi $^{1}$ \\ Yaser Fathy Hussein ${ }^{5}$ \\ ${ }^{1}$ Department of Conservative Dentistry, Faculty of Dentistry, Alexandria University, Alexandria, Egypt; ${ }^{2}$ Department of \\ Conservative Dentistry, Faculty of Dentistry, Cairo University, Cairo, Egypt; ${ }^{3}$ Department of Conservative Dentistry, Faculty of \\ Dentistry, Minia University, Minia, Egypt; ${ }^{4}$ Dental Material, Faculty of Dentistry, Alexandria University, Alexandria, Egypt; ${ }^{5}$ Dental \\ Material, Faculty of Dentistry, Minia University, Minia, Egypt
}

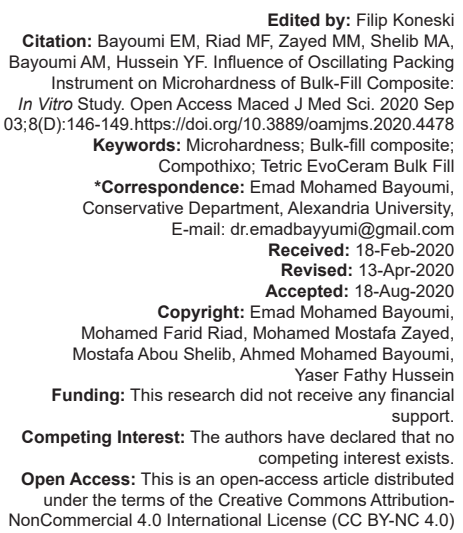

\section{Abstract}

AIM: This study aimed to assess Vickers microhardness of Tetric EvoCeram Bulk Fill composite that was packed manually and using oscillating packing device.

MATERIALS AND METHODS: Two different packing techniques were applied on Tetric EvoCeram Bulk Fil composite. For each packing technique, ten specimens $(6 \mathrm{~mm}$ in diameter and $4 \mathrm{~mm}$ height) were prepared using a black-shaded Teflon mold. The resin was inserted in a bulk increment either packed manually or using Compothixo oscillating device and then light-cured for $40 \mathrm{~s}$. Microhardness was analyzed at the top and the bottom surfaces.

RESULTS: Overall, for both packing techniques, microhardness decreased significantly with the increase of depth Tetric EvoCeram Bulk Fill composite when packed either manually or using oscillating device, did not show significant difference neither at the top surfaces of both applied techniques nor at the bottom surfaces of both applied techniques. CONCLUSION: Different packing techniques did not influence the microhardness of Tetric EvoCeram Bulk Fil composite.

\section{Introduction}

Techniques of bulk filling have become widely used following the development of materials with improved curing [1], [2], controlled polymerization contraction stresses [3], [4]. These materials are suitable for insertion in a $4 \mathrm{~mm}$ bulk placement due to their reduced polymerization stress and their high reactivity to light-curing [5]. The use of the bulk-fill technique undoubtedly simplifies the restorative procedure and saves clinical time. All modern composite resins exhibit some degree of stickiness, resulting in a frustrating phenomenon commonly referred to as "pull-back" [6], so it is important for the composite not to stick to the dental instruments, and still important for it to stick to the cavity walls [7], [8]. Applicability and stickiness of dental composites are influential factors for the properties of those materials and so indirectly affect function, longevity, and esthetics of composite restorations in the clinic.

A newly invented technique was introduced during the past years to temporary enhance the handling and flowability of the composites during application. This procedure uses specific oscillating action, after which the composite returns to its hard consistency. Thereby, the need for flowable composite placement underneath the restoration is eliminated [9], [10]. This new oscillating packing technique for composite placement uses high speed, definite back-and-forth action to the composite material that immediately reduces its viscosity, allowing it to flow much more freely [11]. Furthermore, because the oscillating placement blade strikes the material and withdraws so quickly, the material does not have time to adhere to the placement blade and therefore does not stick. Thus, pull-back is eliminated [12]. Thus, a condensable material with increased viscosity can be used similar to a flowable composite, without the disadvantage of high polymerization shrinkage and poor mechanical properties [13]. This study aimed to assess the microhardness of the Tetric EvoCeram Bulk Fill composite that was packed manually and using Compothixo oscillating packing devices. The null hypothesis tested was that there would be no differences in hardness with different packing techniques using Tetric EvoCeram Bulk Fill composite. 


\section{Materials and Methods}

The study was conducted using the following tested material and device, which are shown in (Tables 1 and 2): Tetric EvoCeram Bulk Fill composite (Ivoclar Vivadent Schaan, Liechtenstein). Compothixo packing device was used (Kerr, USA).

Table 1: The material used in the study, composition, and manufacturers

\begin{tabular}{lll}
\hline Product & Composition & Manufacture \\
\hline Tetric EvoCeram Bulk Fill & The resin material: Bis-GMA, UDMA, and & IvoclarVivadent \\
& Bis-EMA & \\
& The filler: Ytterbium, fluoride, barium, \\
& aluminum, and silicate glass & \\
& Filler size: $550 \mathrm{~nm}$ (mean) & \\
& Filler loading: $80 \% \mathrm{wt}$ & \\
& Shade: IVA & \\
\hline
\end{tabular}

\section{Preparation of the specimens}

Two equally divided groups of total of 20 specimens were prepared using a black-shaded Teflon mold with $6 \mathrm{~mm}$ in diameter and $4 \mathrm{~mm}$ in height. Group I, where the mold cavity was filled with a single bulk increment of Tetric EvoCeram Bulk Fill composite packed manually without the use of Compothixo device, while, for Group II, the mold cavity was filled with a single bulk increment of Tetric EvoCeram Bulk Fill composite packed with the Compothixo device.

Table 2: The instrument used in the study and manufacturers

\begin{tabular}{ll}
\hline Packing instrument & Manufacturer \\
\hline Compthexio & Kerr, USA
\end{tabular}

Compothixo device is characterized by utilizing oscillation vibratory action which produces frequency of $140 \mathrm{~Hz}$, thus providing superior adaptation, reduced air bubbles, reduce stickiness, and no pull-back effect of composite resin. All specimens were covered with a clear polyester transparent matrix strip and a $1 \mathrm{~mm}$ thick glass slide, which was gently pressed under a load of $200 \mathrm{gf}$ for $1 \mathrm{~min}$. The specimens were light-cured for $40 \mathrm{~s}$ with an LED light-curing unit (Bluephase, Ivoclar Vivadent) with a power density of $1200 \mathrm{~mW} / \mathrm{cm}^{2}$. The intensity of the light-curing unit was verified using Bluephase Meter II dental radiometer (Bluephase Meter II, Ivoclar Vivadent). The curing tip of the curing unit was placed as close as to the transparent matrix, which was applied in contact with the top surfaces of the specimens. The matrix was after that removed, thus providing discs with the same dimensions of the mold cavity $(6 \mathrm{~mm}$ diameter and 4 $\mathrm{mm}$ height). All specimens were fabricated and stored in a lightproof receptacle with distilled water at $37^{\circ} \mathrm{C}$. Specimens were tested using Vicker's microhardness test (Leco Co. Michigan, USA.) under the weight of $1000 \mathrm{~g}$ for $15 \mathrm{~s}$, load cell of the universal testing machine was calibrated using predetermined weights, while the crosshead speed was calibrated using digital speed meter. Vicker's microhardness number (VHN) was measured by dividing the load applied by the surface area of the indentation through this formula:
$\mathrm{VHN}=\frac{P}{D^{2}} \times \mathrm{C} \quad(\mathrm{VHN}=$ Vicker's microhardness test, $\mathrm{P}=$ Load applied equals $1000 \mathrm{gm}$, D2=Diagonal length square of the indentation, and $\mathrm{C}=$ Constant equal 1.854 ). Three indentions were made on the top and the bottom surface of each of the specimens, the mean value for the top, as well as the bottom of the specimens were obtained and statistically analyzed. A single-experienced endodontist performed all specimens preparation to avoid interoperator variability, all steps were done under magnification ( $\times 2.5$ magnification EyeMag Smart Loupes; Carl Zeiss Meditec; Jena, Germany). Another experienced operator (A.B) performed the testing procedures and data collection.

\section{Statistical analysis of the data}

Data were collected and entered into the computer using SPSS (Statistical Package for the Social Science) program for statistical analysis version 21. Kolmogorov-Smirnov test of normality revealed significance in the distribution of the variables, so the non-parametric statistics were adopted. Data were described using minimum, maximum, median, and inter-quartile. Comparisons were carried out between two studied independent not normally distributed subgroups using the Mann-Whitney U-test. Comparisons were carried out between more than two studied independent not normally distributed subgroups using the Kruskal-Wallis test. An alpha level was set to $5 \%$ with a significance level of $95 \%$, and a beta-error accepted up to $20 \%$ with a power of study of $80 \%$.

\section{Results}

Vickers microhardness median (IQR) recorded at the top, and the bottom surfaces of tested composite resin packed manually or by oscillating device were displayed on Table 3. Tetric EvoCeram Bulk Fill composite resin applied using different packing techniques showed higher statistical significance at the top surfaces of the specimens compared to the bottom $(p<0.05)$.

Table 3: Descriptive statistics for top and bottom surfaces for the tested material applied using different techniques

\begin{tabular}{|c|c|c|c|}
\hline $\begin{array}{l}\text { Surface of the } \\
\text { specimens }\end{array}$ & $\begin{array}{l}\text { Tetric EvoCeram } \\
\text { Bulk Fill composite }\end{array}$ & $\begin{array}{l}\text { Tetric EvoCeram Bulk } \\
\text { Fill composite using } \\
\text { Compothixo }\end{array}$ & $\begin{array}{l}\text { Test of significance } \\
\mathrm{p} \text { value }\end{array}$ \\
\hline \multicolumn{4}{|l|}{ Top } \\
\hline $\mathrm{n}$ & 10 & 10 & \multirow{4}{*}{$\begin{array}{l}Z_{(M W)}=0.721 \\
p=0.471 \mathrm{NS}\end{array}$} \\
\hline Min-Max & $51.00-64.00$ & $52.60-59.40$ & \\
\hline Median (IQR) & $52.90(52.60-59.20)$ & $54.10(52.90-58.00)$ & \\
\hline $95 \% \mathrm{Cl}$ for mean & $52.0336-58.2664$ & $53.1446-57.0154$ & \\
\hline \multicolumn{4}{|l|}{ Bottom } \\
\hline $\mathrm{n}$ & 10 & 10 & \multirow{5}{*}{$\begin{array}{l}Z_{(M M)}=0.986 \\
p=0.324 N S\end{array}$} \\
\hline Min-Max & $42.00-53.00$ & $43.10-49.60$ & \\
\hline Median (IQR) & $43.90(43.10-47.60)$ & $44.80(43.90-48.00)$ & \\
\hline $95 \% \mathrm{Cl}$ for mean & $42.8124-48.1676$ & $43.9306-47.0894$ & \\
\hline $\begin{array}{l}\text { Chi-square } \\
\text { P }\end{array}$ & $\begin{array}{l}Z_{(M M)}=3.330 \\
p=0.001^{*}\end{array}$ & $\begin{array}{l}Z_{(M W)}=3.782 \\
p=0.000^{*}\end{array}$ & \\
\hline
\end{tabular}


The manual or oscillating technique applied to Tetric EvoCeram Bulk Fill composite resin did not show a statistically significant difference between them neither when compared at the top surfaces $\left(Z_{(\mathrm{MW})}==0.721\right.$, $p=0.471)$ nor when compared at the bottom surfaces $\left(Z_{(\mathrm{MW})}==0.986, \mathrm{p}=0.324\right)$.

\section{Discussion}

The basic principle, as with all common measures of hardness, is to observe the questioned material's ability to resist plastic deformation from a standard source. In the present study, the Vickers hardness test was used to measure the hardness of composite as it can be used for all materials and has one of the widest scales among hardness tests. Hardness values were obtained at different points from the top and the bottom, median values were then calculated [14]. In microhardness test, a black Teflon mold was used instead of transparent molds that might leadlight to penetrate through the sidewalls of the mold and thus helping in curing the specimens of the sidewalls, while, in fact, bulk-filled composite resin was to be evaluated in term of microhardness at the bottom surfaces of the specimens to know the ability of the curing light penetration to the specimens.

In the present study, the microhardness of resin composite decreased as the resin thickness increased [15], where at the top surfaces of the specimens sufficient light energy reached photoinitiator, thus started the polymerization reaction, where its intensity was greatly decreased due to absorption and dispersion of light by filler particles and resin matrix, which lead to the decrease in hardness level from the top surface to the bottom surface, and this might explain the significant difference between the top and the bottom surfaces hardness for all tested groups. Moreover, Tetric EvoCeram Bulk Fill composite has large pre-polymerized fillers which are embedded in an already polymerized organic matrix, which might influence the decreased depth of cure and microhardness at the bottom surfaces [16]. These results were in agreement with the previous studies published elsewhere [16], [17], [18] that reported that the resin hardness at the bottom surfaces of bulk-fill composites resin was significantly different from that at the top when the specimens were $4-5 \mathrm{~mm}$ thickness and in contrast with the manufacturer's instructions, which suggest the application of bulk-fill composite resins in $4 \mathrm{~mm}$ increment.

Tested composite resin packed with different packing techniques exhibited different microhardness values at the top and at the bottom surfaces where Tetric EvoCeram Bulk Fill composite packed by Compothixo oscillating device showed the highest microhardness values, followed by Tetric EvoCeram Bulk Fill composite packed manually without the use of Compothixo oscillating device, where no statistically significant difference between the two packing techniques was reported. Although, when high oscillation energy of Compthixo device (140 HZ) was used, the highest microhardness values were recorded due to immediate reduction in the viscosity of the composite resin thus allowing it to temporary flow much more freely and improve its handling during placement, but unfortunately, the viscosity of the material was not decreased enough with the oscillation energy generated from the Compothixo packing device to generate significant results. These results were in disagreement with the previous studies published by Didem and Gozede [19], Yousef and Ibrahim [20], and Kalra and Bindal [21] that reported higher statistically significant difference for SonicFill composite resin packed and applied using a vibrating handpiece, which is the most similar material applying the concept of oscillation packing as our study. They concluded that the special rheological modifiers in the filler system of the SonicFill composite resin have a dramatic reaction to the sonic energy applied through the handpiece during placement where on activation, the sonic energy reduces the viscosity up to 84 percent and extruded the composite that had a thick consistency initially creating adaptation similar to flowable composites, thus increasing microhardness. Another explanation for the non-significant difference between the different packing techniques applied for Tetric EvoCeram Bulk Fill composite resin might be due to the recent development in dental resin technology which was introduced by Tetric EvoCeram Bulk Fill composite resin to enhance the depth of cure, where besides having a regular camphorquinone/amine initiator system, it has introduced an "initiator booster"(Ivocerin) [22] able to polymerize the material in depth which leads to increased microhardness values regardless the advantage of using the power of oscillating energy in increasing the microhardness of the composite.

\section{Conclusion}

Different packing techniques did not influence the microhardness of Tetric EvoCeram Bulk Fill composite.

\section{Research Ethical Approval}

This study was made with the approval of the ethical committee of Conservative Department, Faculty of Dentistry, Minia University. 


\section{References}

1. Leprince JG, Palin WM, Hadis MA, Devaux J, Leloup G. Progress in dimethacrylate-based dental composite technology and curing efficiency. Dent Mater. 2013;29(2):139-56. https:// doi.org/10.1016/j.dental.2012.11.005

PMid:23199807

2. Czasch P, llie N. In vitro comparison of mechanical properties and degree of cure of bulk fill composites. Clin Oral Investig. 2013;17:227-35. https://doi.org/10.1007/s00784-012-0702-8 PMid:22411261

3. Ilie N, Hickel R. Investigations on a methacrylate-based flowable composite based on the SDR ${ }^{\mathrm{TM}}$ technology. Dent Mater. 2011;27(4):348-55. https://doi.org/10.1016/j.dental.2010.11.014 PMid:21194743

4. El-Damanhoury H, Platt J. Polymerization shrinkage stress kinetics and related properties of bulk-fill resin composites. Oper Dent. 2014;39(4):374-82. https://doi.org/10.2341/13-017-I PMid:23865582

5. Alshali RZ, Salim NA, Satterthwaite JD, Silikas N. Post irradiation hardness development, chemical softening and thermal stability of bulk-fill and concentional resin composites. J Dent. 2015;43(2):209-18. https://doi.org/10.1016/j.jdent.2014.12.004 PMid:25511301

6. Draughn RA, Leinfelder KF. The Use of Oscillation in the Placement of Composite Materials. Dentaltown Magazine; 2011. p. 94-6.

7. Al-Sharaa KA, Watts DC. Stickiness prior to setting of some light cured resin-composites. Dent Mater. 2003;19(3):182-7. https:// doi.org/10.1016/s0109-5641(02)00097-0

PMid:12628429

8. VanDiijken JW, Sunnegardh-Gronberg K. A two-year clinical evaluation of a new calcium aluminate cement in Class II cavities. Acta Odontol Scand. 2003;61(4):235-40. https://doi. org/10.1080/00016350310004575 PMid: 14582592

9. Her SC, Lin CS. Vibration analysis of composite laminate excited by piezoelectric actuators. Sensors (Basel). 2013;13(3):29973013. https://doi.org/10.3390/s130302997

PMid:23529121

10. Garcia D, Yaman P, Dennison J, Neiva G. Polymerization shrinkage and depth of cure of bulk fill flowable composite resins. Oper Dent. 2014;39(4):441-8. https://doi.org/10.2341/12-484-I PMid:24304339

11. Santhosh L, Bashetty K, Nadig G. The influence of different composite placement techniques on microleakage in preparations with high C factor: An in vitro study. J Conserv Dent. 2008;11(3):112-6. https://doi.org/10.4103/0972-0707.45249

\section{PMid:20142897}

12. Ozcan M, MeseA. Effect of ultrasonic versus manual cementation on the fracture strength of resin composite laminates. Oper Dent. 2009;34(4):437-42. https://doi.org/10.2341/08-112 PMid: 19678449

13. Choi JH, Lee S, Lee JW. Non-Newtonian behavior observed via dynamic rheology for various particle types in energetic materials and simulant composites. Korea-Aust Rheol J. 2017;29:9-15. https://doi.org/10.1007/s13367-017-0002-6

14. Colombo M, Poggio C, Lasagna A, Chiesa M, Scribante A. Vickers micro-hardness of new restorative CAD/CAM dental materials: Evaluation and comparison after exposure to acidic drink. Material. 2019;12:1246. https://doi.org/10.3390/ ma12081246

PMid:31014032

15. Moore BK, Platt A, Borgs G, Chu TM. Depth of cure of dental resin composites: ISO4049 depth and microhardness of types of material and shades. Oper Dent. 2008;33:408-12. https://doi. org/10.2341/07-104

16. Shalan LA, Thiab SA. The effect of different light cure systems on microhardness of bulk composite materials. J Bagh Coll Dent. 2017;29:13-20. https://doi.org/10.12816/0038744

17. Kim E, Jung $\mathrm{H}$. Effect of resin thickness on the microhardness and optical properties of bulkfill resin composites. Restor Dent Endod. 2015;40(2):128-35. https://doi.org/10.5395/ rde.2015.40.2.128

PMid:25984474

18. Ciccone-Nogueira JC, Borsatto MC, de Souza-Zaron WC, Ramos RP, Palma-Dibb RG. Microhardness of composite resin at different depths varying the post irradiation time. J Appl Oral Sci. 2007;15(4):1657-78. https://doi.org/10.1590/ s1678-77572007000400012

PMid: 19089149

19. Didem A, GozedeY. Comparative mechanical properties of Bulkfill resin. Open J Compos Mater. 2014;4:117-21.

20. Yousef $M K H$, Ibrahim A. Effect of different light curing units on microhardness of different bulkfill materials. Life Sci J. 2015;12:24-30.

21. Kalra K, Bindal D. A novel sonicfill composite system used for bulk fill posterior restorations. Int J Dent Oral Health. 2017;3:112-6.

22. Moszner N, Fischer UK, Ganster B, Liska R, Rheinberger V. Benzoyl germanium derivatives as novel visible light photoinitiators for dental materials. Dent Mater. 2008;24(7):9017. https://doi.org/10.1016/j.dental.2007.11.004

PMid:18155290 